\title{
Adverse Drug Reactions Reporting among Health Professionals in Government Hospitals in Katsina State, Nigeria
}

\author{
Ayuba Daniel $^{1 *}$, Abdullahi Sabo Muhammad ${ }^{2}$ \\ ${ }^{1}$ Department of Public Health, Texila American University, Guyana \\ ${ }^{2}$ Department of Physical and Health Education, College of Technical and Vocational \\ Education, Kaduna polytechnic, Kaduna Nigeria
}

\begin{abstract}
Medicines have the potential to cause Adverse Drug Reactions (ADRs) and therefore the need for health professionals to detect and spontaneously report to the National Agency for Food and Drug Administration and Control (NAFDAC) for further actions to ensure patients and public safety. The study was conducted to ascertain the proportion and reporting procedures of ADRs reported by health professionals in the Government Hospitals in Katsina State, Nigeria. This was a crosssectional survey of 392 health professionals randomly selected from the 19 secondary hospitals in Katsina state. Data were collected through a self-administered structured questionnaire from 18th January to 19th February 2021 with a $98.7 \%$ and 1.3\% response rate. Data were analyzed using STATA software Version 15.0. Descriptive statistics were used to describe the background characteristics of respondents, and the outcome, such as the proportion of ADR reported summarized in percentages, frequencies, and charts. There was only a $28.3 \%$ ADRs reporting rate, and $25.1 \%$ of health professionals who saw an ADRs case reported it by completing the ADRs form. The level of knowledge on ADRs reporting procedures was $58.3 \%$ among respondents. The main systemic challenge with ADRs reporting was the lack of access to the reporting form for ADRs. Therefore, there is a need to improve access to the reporting form in all the hospitals.
\end{abstract}

Keywords: Adverse Drug Reaction Reporting, Government Hospitals, Health Professionals, Katsina state, Nigeria, Reporting Rate.

\section{Introduction}

Adverse Drug Reactions (ADRs) are global public health problems. In its severe form, it may cause hospital admission, morbidity, and mortality [1]. Adverse Drug Reaction (ADR) is an untoward response to a medicinal product that is noxious and unintended, including the absence of efficacy, and that happens at any dose and may result from the use of the product under the terms of the marketing authorization, the use of the product outside the terms of the marketing authorization, including overdose, off-label use, misuse, abuse and mistakes in medication [2].
Out of the several methods of detecting ADRs, the Spontaneous system of reporting is widely used and is the cheapest system for monitoring the safety of a medicine in real life [3]. This method is largely dependent on ADR reporting by healthcare providers. Data gathered from drug monitoring activities enable drug regulatory authorities to make evidencebased decisions with regard to the safety and rational use of drugs.

Previous studies from different regions in Nigeria have concentrated on the perception and practice of ADRs reporting among physicians only while excluding other cadres of 
healthcare workers $[4,5 ; 6]$. The achievement of safe medicine and patient safety is not within the jurisdiction of one discipline. For instance, ADR has an economic burden on the health system and the patients [7]. Therefore, effective pharmacovigilance is achievable where a team with the requisite training, knowledge, and responsibility for it is aware of its expected public health roles in that regard and is willing, able, and disposed to work together to perform it [8]. The conduct of this study assesses only the ADR aspect of the pharmacovigilance system. The findings, in part, will contribute to the provision of relevant information on ADR reporting and how responsive the system is. It will also identify some possible challenges with the system to inform policymakers about suggestive ways to strengthen or improve the current guidelines or policy direction.

The World Health Organization has laid series of emphasis on pharmacovigilance [9]. Despite this and locally directed efforts such as the National ADR reporting scheme in Nigeria, there is still a low rate of ADRs reporting by health care providers [10].

\section{Methods}

\section{The study Area/Setting}

Katsina State was created on September 23rd, 1987. It has an area of 23,938 square kilometers and a population of 5.97 million people based on 2003 population census figures at a $3.0 \%$ constant annual growth rate in 2007 , and this indicates a population density of about 249 persons per square kilometre [11]. It is located approximately between latitude 11007 ' $49 "$ and 13020 ' 00 " $\mathrm{N}$ and between longitude 60 52' 03 " and 9002 ' 40" E. it is boarded to the North by the Niger Republic, to the East by Jigawa and Kano States, to the south by Kaduna State and the West by Zamfara State. The State covers an area of about $24,192 \mathrm{~km} 2$.

In 2003, there was 18 Hospital in Katsina State with 1,643 beds and a bed/population ratio of 1:3:13. By the end of 2007, the total number of hospitals in the State increase to 19, representing a $5.5 \%$ increase, while the available beds increased to $2885 \quad(76.6 \%$ increase) and the bed/population rate stood at $1 / 2,068$ persons [11].

\section{Study Design}

A cross-sectional descriptive approach was employed to undertake the study among health professionals in Government hospitals in Katsina state using a structured questionnaire to collect quantitative data. The type of data collected was tightly pre-specified on the questionnaires before the data collection. It focused on pre-defined variables to be measured.

\section{The Study Population}

The study population was healthcare professionals in the 19 secondary hospitals in Katsina state. These include Doctors, Nurses, Midwives, and Pharmacy staff who practiced in the hospital for the past twelve months at the time of the conduct of this study.

\section{Sampling Procedure}

Simple random sampling was done to select the respondents. The investigator visited all the Departments and units where the various cadre of the health professionals work and folded papers with "YES" and "NO" inscriptions on them. The folded papers were put in a container and presented to prospective respondents to select. Those that select "YES" during each visit were included in the study. Those that picked "NO" had the chance to be selected in the subsequent sampling procedure. This procedure was done two times in each ward for the period of the data collection. Due to the small numbers of prescribers, pharmacy staff and midwives, all those that were at the post during the period of data collection were all included in the study.

\section{Inclusion and Exclusion Criteria}

Doctors, Nurses, Midwives, and pharmacy staff (pharmacist, pharmacy technicians, and dispensing assistants), who have been involved 
in clinical care for at least twelve months at the time of this study were included. Other cadres and those who were less than a year in clinical practice were excluded. Students and personnel on internship under the categories stated above were also excluded.

\section{Sample Size Determination}

Three hundred and ninety-two (392) health professionals are estimated to take part in the study. The minimum sample size for the research was calculated using the Cochran, 1963 [12] formula as follows:

$$
S S=\frac{Z^{2} p(1-p)}{C^{2}}
$$

ss $=$ sample size

$\mathrm{Z}=\mathrm{Z}$ value (1.96 for $95 \%$ confidence level).

$\mathrm{p}=$ percentage picking a choice, expressed as decimal.

$\mathrm{c}=$ confidence interval, expressed as decimal.

Using a $36.6 \%$ ADR reporting rate among health professional in Nigeria (Fadare et al, 2011), $\mathrm{p}=0.366$ Allowable margin of error $(\mathrm{C})$ is $5 \%=0.05$.

The $\mathrm{z}$ value corresponding to a $95 \%$ confidence interval $=1.96$.

The above parameters were substituted into the formula to get the minimum sample size required for the study as follows;

$$
N=\frac{1.96^{2}(0.366)(1-0.366)}{0.05^{2}}=356.5
$$

Adjusting for a non-response rate of $10 \%$, a minimum sample size of 392 was finally obtained.

\section{Data Collection Instrument and Procedure}

Structured questionnaires were used as a tool to collect the data. Each questionnaire consisted of five sections. Part "A" covered the sociodemographic data of the respondents, section " $\mathrm{B}$ " comprised of nine knowledge questions with two options of "YES" for having knowledge and "NO" for not knowing ADR reporting, section " $\mathrm{C}$ " covered the proportion of
ADR reported by health professionals, section "D" sought data on challenges of ADR reporting and the last section solicited data on how to improve ADR reporting. Since all respondents were literates, the questionnaires were distributed to participants, and clarifications made on questions that respondents did not understand and later be retrieved by the principal investigator. Respondents that had time and answered the questionnaires outright were retrieved the same day. Those that could not be given at most 72 hours to answer and return them.

\section{Pretest and Validation of the Instrument}

The questionnaires were pretested at the Alheri Clinic, Katsina though no changes were made apart from few typographical errors that were corrected. The literature and the research objectives guided the validity of the design of the questionnaire. No data collection assistant was recruited. Participants that were busy and could not immediately answer the questionnaire were given a maximum of three days to return the answered questionnaire.

\section{Ethical Approval}

The Katsina state ministry of Health Ethics Committee has approved (MOH/ADM/SUB/1152/1/419) the conduct of the study. Written permission was obtained from Hospital services management Board, Katsina to use the hospitals as the study site and their health professionals as the study participants.

\section{Data Analysis}

The unit of analysis was the cadre of health professionals. Questionnaires were sorted and screened for errors. Data were first entered into Microsoft Excel, cleaned and coded before being exported to STATA software version 15.0 for analysis. The characteristics of respondents such as age were described in mean and standard deviation. All background characteristics were also summarized and 
presented in frequencies and percentages. The outcome variable was described in frequencies and proportions.

\section{Results}

\section{Background \\ Respondents}

Characteristics

of

A total of 387 health professionals took part in the study. Table 1 shows that most health professionals were within the 30-39 age category representing $48 \%(n=186)$ of the total respondents. The 20-29 age category formed $32.8 \%(\mathrm{n}=127)$. The least age group (19\% $\mathrm{n}=74$ ) was those that were 40 years and above. Over half $(62.5 \% \mathrm{n}=242)$ were females, with the males forming less than half (37.5 $n=145)$. Over half of them were married $(85 \% \mathrm{n}=331)$, while the rest were not married. Out of the three hundred and eighty-seven participants, the highest $(39 \%, \mathrm{n}=151)$ were nurses, $9.3 \%(\mathrm{n}=36)$ midwives, $22.7 \%(\mathrm{n}=88)$ pharmacy staff and (28.9\%, $\mathrm{n}=112$ ) being the Medical Doctors. A good number of the health professionals were young in practice with 4-6 years of work experience and constituted $32.6 \%(n=126)$ of the total respondents. An appreciable number $(\mathrm{n}=73,18.9 \%),(\mathrm{n}=71,18.3 \%)$ had also worked for 1-3 and 7-9 years respectively, while 14\% $(n=54)$ had worked for sixteen or more years at the time of this study.

Table 1. Background Characteristics of Respondents

\begin{tabular}{|l|l|l|}
\hline Variable name & Frequency $(\mathbf{n}=\mathbf{3 8 7})$ & Percentage (\%) \\
\hline Age (years) & 127 & 33 \\
\hline $20-29$ & 186 & 48 \\
\hline $30-39$ & 74 & 19 \\
\hline$>=40$ & 145 & 37.5 \\
\hline Sex & 242 & 62.5 \\
\hline Male & \multicolumn{2}{|l|}{} \\
\hline Female & 14.5 \\
\hline Marital status & 56 & 85.5 \\
\hline Not married & 56 \\
\hline Married & 331 & 28.9 \\
\hline Cadre of staff & \multicolumn{2}{|l|}{} \\
\hline Medical Doctor & 112 & 22.7 \\
\hline Pharmacy staff & 88 & 39 \\
\hline Nurses & 151 & 9.3 \\
\hline Midwives & 36 & 18.9 \\
\hline Years of practice & 32.6 \\
\hline $1-3$ & 73 & 18.3 \\
\hline $4-6$ & 126 & 16.2 \\
\hline $7-9$ & 71 & 14 \\
\hline $10-15$ & 63 & \\
\hline$>=16$ & 54 & \\
\hline
\end{tabular}

\section{ADR Reporting}

The summary in Table 2 and Table 3 shows that in the past twelve months $117(30.2 \%)$ patients reported ADR to the health professionals, while patients did not approach almost $70 \%$ on issues related to ADR. About 1,239 cases of ADR were reported by patients to the HCPs within the months under review. 
Table 2. Proportion of Adverse Drug Reaction Reported by Patients through the HCPs.

\begin{tabular}{|l|l|l|}
\hline Variable Name & Frequency $(\mathbf{n = 3 8 7})$ & Percentage (\%) \\
\hline \multicolumn{2}{|c|}{ Any patient reported an ADR to you in the past year } \\
\hline No & 270 & 69.8 \\
\hline Yes & 117 & 30.2 \\
\hline
\end{tabular}

Table 3. Cases of Adverse Drug Reaction Reported by Patients to HCPs

\begin{tabular}{|l|c|c|c|}
\hline Response & Frequency $\mathbf{( n = 3 8 7 )}$ & Cumulative Response & Percentage (\%) \\
\hline 0 & 103 & 0 & 0 \\
\hline 1 & 35 & 35 & 2.8 \\
\hline 2 & 53 & 106 & 8.6 \\
\hline 3 & 50 & 150 & 12.1 \\
\hline 4 & 47 & 188 & 15.2 \\
\hline 5 & 23 & 115 & 9.3 \\
\hline 6 & 15 & 90 & 7.3 \\
\hline 7 & 5 & 35 & 2.8 \\
\hline 8 & 9 & 72 & 5.8 \\
\hline 9 & 2 & 18 & 1.5 \\
\hline 10 & 7 & 70 & 5.6 \\
\hline 11 & 1 & 11 & 0.9 \\
\hline 12 & 4 & 48 & 3.9 \\
\hline 13 & 1 & 13 & 1.0 \\
\hline 14 & 1 & 14 & 1.1 \\
\hline$>=15$ & 31 & 274 & 22.1 \\
\hline Total & 387 & 1,239 & 100 \\
\hline
\end{tabular}

The summary in Table 4 shows that 322 $(83.2 \%)$ of health professionals ever encountered a patient with suspected ADR in the past twelve months. Out of 322 participants who saw ADR cases, only $(25.1 \%, \mathrm{n}=97)$ reported it by completing the ADR form, while the majority $(74.9 \%, \mathrm{n}=290)$ however did not report it.

Table 4. The Proportion of Adverse Drug Reaction Reported by a Health Professional

\begin{tabular}{|l|l|l|}
\hline Variable Name & Frequency $(\mathbf{n}=\mathbf{3 8 7})$ & Percentage (\%) \\
\hline \multicolumn{2}{|l|}{ Ever seen a patient with ADR for the past year } \\
\hline No & 65 & 16.8 \\
\hline Yes & 322 & 83.2 \\
\hline \multicolumn{2}{|l|}{ Ever reported ADR $(\mathbf{n = 3 2 2})$} \\
\hline No & 290 & 74.9 \\
\hline Yes & 97 & 25.1 \\
\hline
\end{tabular}

In Figures 1 and 2, the majority $(n=322)$ of health professionals saw a patient with adverse drug response in the past twelve months. More Medical Doctors $(89.28 \%, \mathrm{n}=100)$ than, Pharmacy staff $(73.86 \%, \quad \mathrm{n}=65)$, Nurses (59.60\%, $\mathrm{n}=90)$, and midwives $(47.22 \%, \mathrm{n}=17)$ ever saw adverse drug reaction cases at the time of this study. Less than $30 \% \quad(\mathrm{n}=97)$ of all cadres reported the ADR they saw. The proportion among the pharmacy staff was highest $(87.69 \%, n=57)$, and that of the Nurses was lowest $(55.55 \% \mathrm{n}=50)$ relative to the other cadres. 


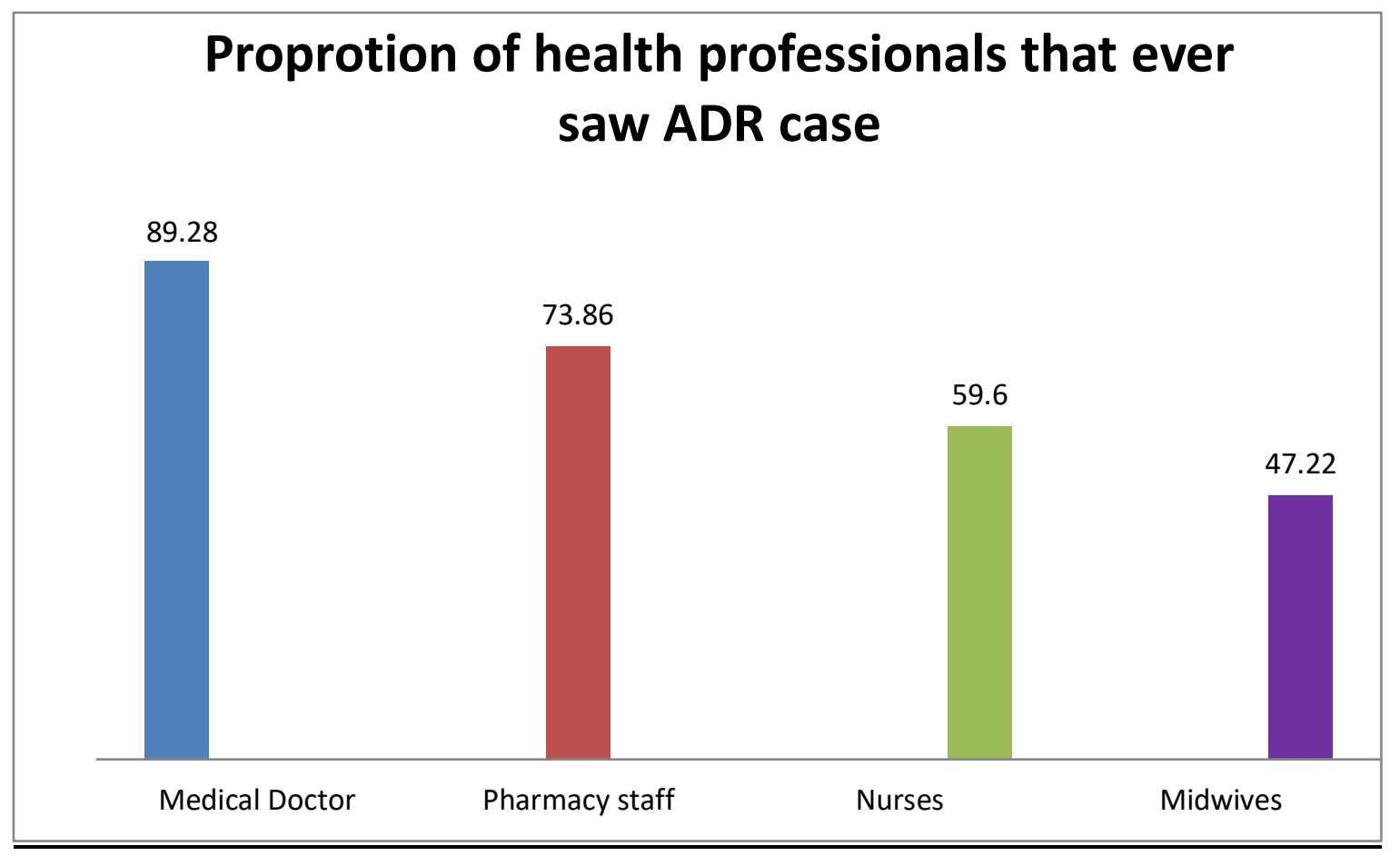

Figure 1. Proportion of ADR Seen by a Cadre

\section{Proprotion of health professionals that ever reproted ADR case}

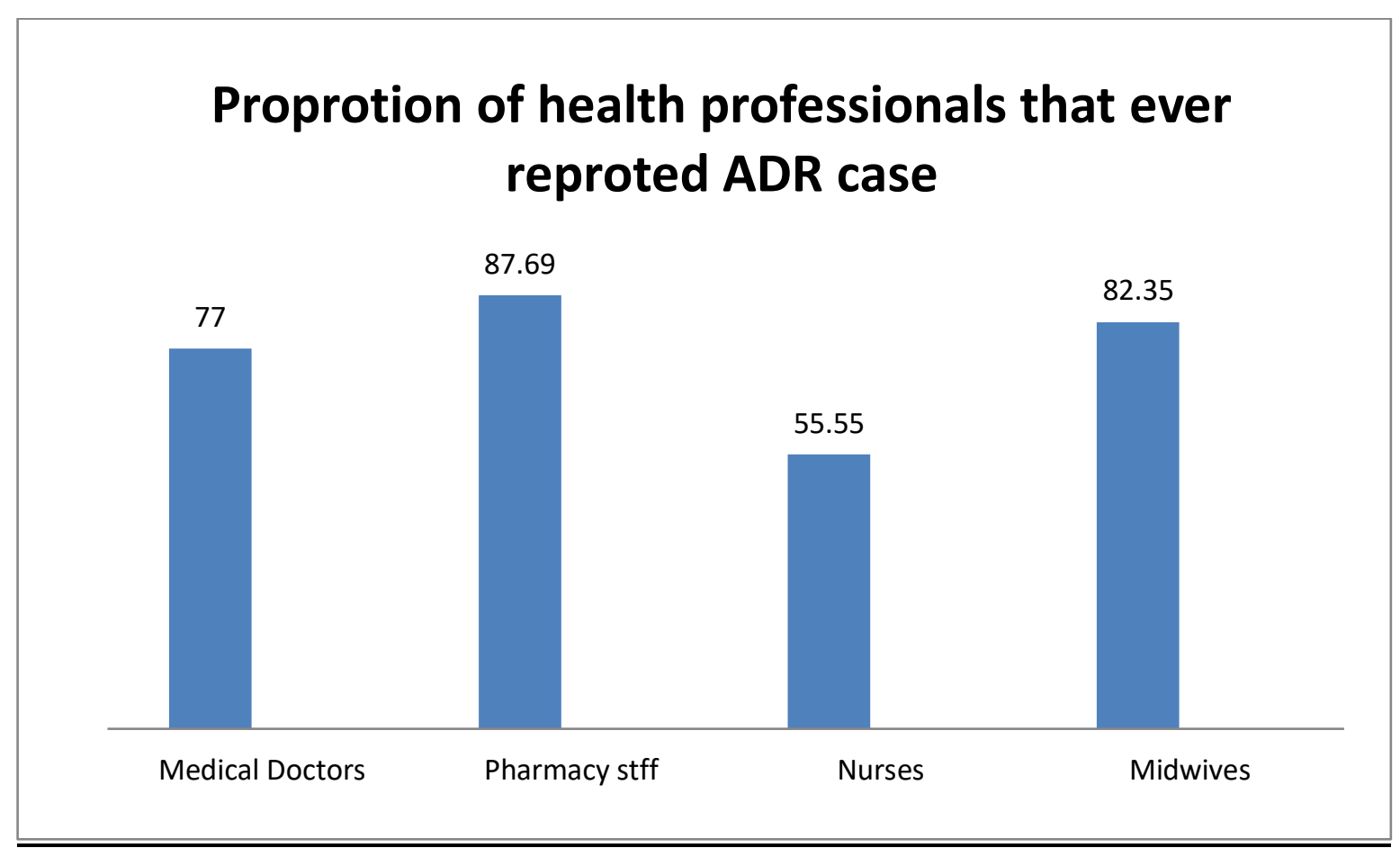

Figure 2. The Proportion of ADR Reported by a Cadre

In Figure 3, only 103(28.3\%) out of 364 adverse drug reaction cases seen for the past year were reported by participants using the
ADR forms. The remaining 261(71.7\%) were not reported. 


\section{Proportion of ADR reported by health professionals}

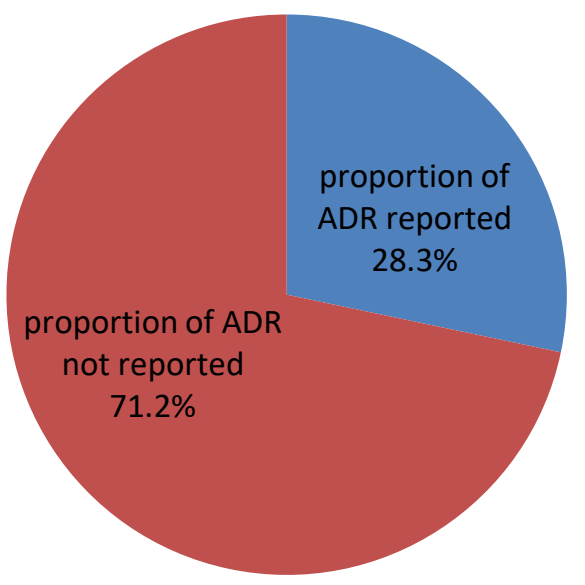

Figure 3. The Proportion of Total ADRs Reported

Respondents ascribed different reasons when they were asked the question of why some ADR cases were not reported. The most $(89.96 \%, n=242)$ cited reason for not reporting ADR was non-availability of the ADR forms followed by not knowing the reporting procedure $(3.72 \%, n=10)$. About $3.35 \%(n=9)$ indicated that they did not report because they considered the reaction to be normal and commonly associated with that medicine. Almost 2.23\% ( $\mathrm{n}=6)$ said they did not know they were supposed to report it. Not thinking that the ADR reporting was important or serious was not a reason for non-reporting. The least $(0.74 \%, \mathrm{n}=2)$ reason for non-reporting was lack of time.

Table 4. Reasons for not Reporting Adverse Drug Reaction

\begin{tabular}{|l|l|l|}
\hline Reasons for not reporting ADR & Frequency & Percent \\
\hline I did not know I was supposed to report & 6 & 2.23 \\
\hline The reporting form was not available & 242 & 89.96 \\
\hline I do not know the reporting procedure & 10 & 3.72 \\
\hline I did not have time to report & 2 & 0.74 \\
\hline I did not think it was important/serious & 0 & 0.00 \\
\hline $\begin{array}{l}\text { I considered it "normal because it is a } \\
\text { common reaction with that medicine }\end{array}$ & 9 & 3.35 \\
\hline
\end{tabular}

\section{Knowledge on Adverse Drug Reaction Reporting}

The summary in Table 5 and 6 regarding the knowledge on ADR reporting procedures portrayed that majority $(88.1 \%, \mathrm{n}=340)$ of respondents ever heard of adverse drug reaction reporting in Nigeria. More Medical Doctors
(100\%, $\mathrm{n}=112)$ and pharmacy staff $(100 \%$, $\mathrm{n}=88$ ) than the other cadres heard about ADR reporting in Nigeria and knew that all health professionals are obliged to report ADRs. Midwives were the least $(94.44 \%, n=34,80.55$, $n=29$ ) that heard of the ADR reporting in Nigeria and also knew that ADR reporting is a professional obligation to all health 
professionals. Cumulatively, 41.5\% ( $\mathrm{n}=160)$ of total respondents knew the tools for reporting ADR in Nigeria. By cadre, all pharmacy staff (88) and nurses (151) knew the ADR reporting tools while $98.21 \%$ and $61.11 \%$ of Medical Doctors and midwives, respectively, also knew the ADR reporting tools. Moreover, 55.2\% knew the types of ADR to be reported. In terms of the reporting procedure, $55.2 \%$ knew where to obtain the ADR forms. More Medical Doctors $(62.50 \%)$ knew where to obtain the ADR forms compared to the pharmacy staff (68.18\%), nurses $(35.76 \%)$, and midwives (52.77\%). About $52.1 \%$ knew the information to put on the ADR form. Also, 37.0\% knew where to submit the filled forms. About $98.21 \%$ of Medical Doctors knew where to return the filled ADR form to, but fewer nurses (39.73) relative to the other cadres knew where to submit the filled ADR form. Generally, as much as $85.0 \%$ thought it was necessary to report ADRs, and $86.3 \%$ knew the reasons for reporting them. By cadre, all Medical Doctors and pharmacy staff thought it necessary to report ADRs and knew the reasons for reporting.

Overall, more than half $(58.3 \%, \mathrm{n}=225)$ of respondents had a high level of knowledge about adverse drug reaction reporting with those that had a low level of knowledge constituting for less than $10 \%$ of the total respondents. Moderately $31.9 \%$ of health professionals knew adverse drug reaction reporting.

Table 5. Knowledge of Health Professionals on ADR Reporting

\begin{tabular}{|l|l|l|}
\hline Level of knowledge criteria & Positive response & Percentage (\%) \\
\cline { 2 - 3 } & Frequency n=386 & \\
\hline $\begin{array}{l}\text { Have you heard about adverse drug reaction } \\
\text { reporting in Nigeria? }\end{array}$ & 340 & 88.1 \\
\hline $\begin{array}{l}\text { Do you know that all health professionals who } \\
\text { directly take care of patients are responsible for } \\
\text { reporting ADRs? }\end{array}$ & 304 & 78.8 \\
\hline $\begin{array}{l}\text { Do you know the tools for reporting ADR in } \\
\text { Nigeria? }\end{array}$ & 160 & 41.5 \\
\hline $\begin{array}{l}\text { Do you know the type of ADRs that are supposed to } \\
\text { be reported? }\end{array}$ & 213 & 55.2 \\
\hline $\begin{array}{l}\text { Do you know where to obtain the reporting tools for } \\
\text { reporting ADRs in your hospital? }\end{array}$ & 137 & 35.5 \\
\hline $\begin{array}{l}\text { Do you know the information that is required on the } \\
\text { ADR form? }\end{array}$ & 201 & 52.1 \\
\hline Do you know where to send the filed ADR form? & 143 & 37.0 \\
\hline Do you think it is necessary to report ADR? & 328 & 85.0 \\
\hline Do you know the reason for reporting ADR? & 333 & 86.3 \\
\hline Level of knowledge on ADR reporting & 38 & 9.8 \\
\hline Low knowledge & 123 & 31.9 \\
\hline Average knowledge & 225 & 58.3 \\
\hline High knowledge & $1-3$ “Y & \\
\hline
\end{tabular}

The level of knowledge was measured using a total score of nine responses. Seven to nine "YES" responses were graded high knowledge, 5-6 "Yes" was graded moderate knowledge, and 1-3 "YES" was considered a low level of knowledge about ADR reporting. 
Table 6. Awareness of Respondents on ADR Reporting Procedures

\begin{tabular}{|l|l|l|l|l|}
\hline \multirow{2}{*}{ Knowledge Questions } & Medical Doctors & Pharmacy Staff & Nurses & Midwives \\
\cline { 2 - 5 } & $\mathbf{n = 1 1 2}$ & $\mathbf{n = 8 8}$ & $\mathbf{n = 1 5 1}$ & $\mathbf{n = 3 6}$ \\
\cline { 2 - 5 } & $\mathbf{f r e q u e n c y ~ ( \% )}$ & frequency (\%) & frequency (\%) & frequency (\%) \\
\hline Have you heard about adverse drug reaction reporting in Nigeria? & $112(100)$ & $88(100)$ & $145(96.02)$ & $34(94.44)$ \\
\hline $\begin{array}{l}\text { Do you know that all health professionals who directly take care of } \\
\text { patients are responsible for reporting ADRs? }\end{array}$ & $112(100)$ & $88(100)$ & $140(92.71)$ & $29(80.55)$ \\
\hline Do you know the tools for reporting ADR in Nigeria? & & & \\
\hline Do you know the type of ADRs that are supposed to be reported? & $110(98.21)$ & $88(100)$ & $100(66.22)$ & $26(61.11)$ \\
\hline $\begin{array}{l}\text { Do you know where to obtain the reporting tools for reporting ADRs } \\
\text { in your hospital? }\end{array}$ & $70(62.50)$ & $65(96.59)$ & $81(53.64)$ & $22(61.11)$ \\
\hline Do you know the information that is required on the ADR form? & $112(100)$ & $75(35.18)$ & $54(35.76)$ & $19(52.77)$ \\
\hline Do you know where to send the filed ADR form? & $110(98.21)$ & $85(96.59)$ & $60(39.73)$ & $18(50.00)$ \\
\hline Do you think it is necessary to report ADR? & $112(100)$ & $88(100)$ & $120(79.47)$ & $35(97.22)$ \\
\hline Do you know the reason for reporting ADR? & $112(100)$ & $88(100)$ & $130(86.09)$ & $29(80.55)$ \\
\hline
\end{tabular}


Though the level of knowledge was generally high among respondents, further analysis showed that Medical Doctors particularly had the highest (100\%) level of knowledge. Nurses had moderate (39.37\%) knowledge while midwives had the least knowledge on ADR reporting procedures with $14.29 \%$ compared to the other cadres, as shown in figure 4 below.

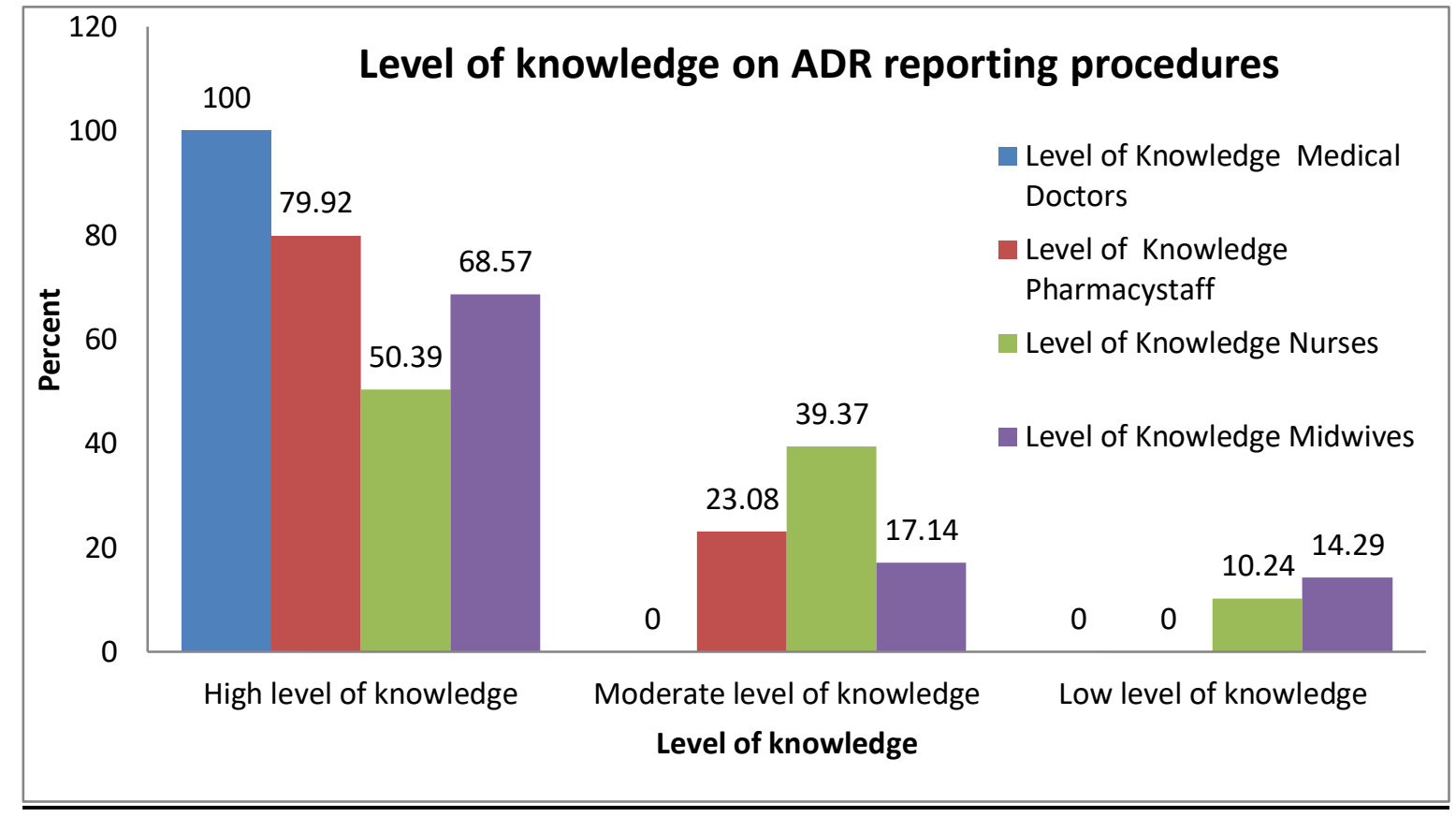

Figure 4. Level of Knowledge of Health Professionals on ADR Reporting Procedures

\section{Challenges with ADR Reporting}

Regarding the question on the challenges with ADR reporting, it was found that Patient's poor knowledge about ADRs (77.4), Lack of campaigns to promote patients ADR reporting to HCPs (84.0), lack of access to the internet
ADR reporting portal (57.9\%), non-availability of the ADR forms (97.2\%), lack of training (70.4\%), and no extrinsic motivation (94.8) were the major challenges in Government hospitals in Katsina state, Nigeria.

Table 7. Systemic Challenges with ADR Reporting

\begin{tabular}{|l|l|l|}
\hline Systemic Challenges & Frequency & Percent \\
\hline Patient's poor knowledge about ADRs & 280 & 72.4 \\
\hline Bias in ADRs reporting by consumers or patients & 159 & 41.2 \\
\hline $\begin{array}{l}\text { Lack of campaigns to promote consumers or patients ADR } \\
\text { reporting to HCPs }\end{array}$ & 375 & 84.0 \\
\hline Non-availability of the ADR forms & 376 & 97.2 \\
\hline Lack of access to the online reporting portal & 224 & 57.9 \\
\hline Internet connectivity & 119 & 30.7 \\
\hline No extrinsic motivation & 367 & 94.8 \\
\hline Lack of in-service training/orientation on ADR reporting & 272 & 70.4 \\
\hline
\end{tabular}

As shown in Table 8, closed to $88 \%$ of respondents thought the WhatsApp platform should be added to existing ADR channels for
ADR. About $30 \%$ chose E-mail as an additional mode of reporting ADR. The majority (97.4\%) of respondents indicated that giving phone 
recharge cards for online reporting will help improve the ADR reporting rate. Less than 3\% (36) did not know whether giving the recharge cards will improve the reporting rate or not. Closed to $100 \%$ indicated that patient education on ADR would further improve ADR reporting. All (100\%) respondents said training of health staff would improve ADR reporting rate. As many as 379 (97.9\%) respondents further thought that the availability of ADR forms is a way of improving ADR reporting whilst only $2.1 \%$ didn't think so. The results also showed that a greater proportion $(93.8 \%)$ of respondents were of the view that integrating ADR reporting into the monthly cases and deaths (CD1) reporting system for diseases under surveillance will also improve the reporting system of ADR.

Table 8. Suggested Ways to Improve ADR Reporting

\begin{tabular}{|l|l|l|}
\hline Ways to improve ADR reporting & Frequency $(\mathbf{n}=\mathbf{3 8 7})$ & Percent \\
\hline Reporting through WhatsApp platform & 340 & 87.9 \\
\hline Reporting through E-mail & 116 & 30 \\
\hline $\begin{array}{l}\text { Giving phone recharge cards as motivation report ADR } \\
\text { online }\end{array}$ & 377 & 97.4 \\
\hline $\begin{array}{l}\text { Patient education on the need to visit the health facility } \\
\text { in times ADR }\end{array}$ & 381 & 98.4 \\
\hline Training of health professionals on ADR reporting & 387 & 100 \\
\hline Availability of ADR forms in all wards & 379 & 97.9 \\
\hline $\begin{array}{l}\text { Will integration of ADR into the weekly cases and } \\
\text { death (CD1) reporting system improves ADR reporting }\end{array}$ & 363 & 93.8 \\
\hline
\end{tabular}

\section{Discussion}

This study revealed that $83.2 \%(n=322)$ of respondents ever saw adverse drug reaction cases, out of which $25.1 \% \quad(n=97)$ reported them by filling the ADR forms. More proportion of prescribers than the other cadres ever saw and reported ADR cases among the different cadres. In contrast, a study conducted in the Volta regional hospital of Ghana on knowledge and attitude among health professionals on pharmacovigilance found that only $16.7 \%$ and $24 \%$ of doctors and nurses had ever reported ADRs by using the blue form [13]. Further studies on healthcare professionals' knowledge on pharmacovigilance and ADR reporting behaviour and factors determining the reporting rates also found a contrasting proportion of ADR reported by healthcare professionals compared to the current studies. About $41 \%$ of ADR seen were reported in their study compared to $25.1 \%$ in the present study [14]. The $89.28 \%(\mathrm{n}=100)$ of Medical Doctors that ever saw ADR aligns with the finding by [15] that showed that more than $50 \%$ of doctors ever saw ADR cases. The proportion $(77.00 \%)$ of Medical Doctors that reported ADRs from the current study, however, differs from the $20 \%$ that [15] observed in their study. In the Indian Maharashtra rural tertiary hospital, more doctors $(59 \%)$ than nurses $(18 \%)$ ever reported ADR [16]. This is similar to the findings from the present study, where more Medical Doctors than nurses reported ADRs in the past 12 months. Only 3\% of respondents who ever encountered ADRs in Saudi Arabia reported it [17]. This is dissociated with about $25 \%$ proportion of health professionals reporting ADRs as documented in this study.

This study found that the proportion of the total number of ADRs reported by respondents was low (28.3\%). This observation agrees with earlier findings from Sokoto that showed as low as 7.0\% ADR reporting rate by clinicians [18]. Patients' failure to report ADRs to their healthcare Providers accounts for the high proportion of ADR not reported by health 
professionals in the past 12 months preceding this study.

Generally, there was high knowledge (88.1\%) on ADR reporting across all cadres of respondents. This supports earlier studies by Adosome in the Volta Regional Hospital of Ghana, which found that Doctors, Pharmacists, and Nurses Prescribers are knowledgeable in pharmacovigilance in Ghana [13]. However, the $78.8 \%$ awareness of the ADR reporting system described in the current study does not support a $39.6 \%$ awareness of healthcare professionals about the domestic pharmacovigilance system documented by Al-Madinah Al-Munawwarah Kingdom of Saudi Arabia [14]. Approximately $70 \%$ of pharmacists in Nigeria did not know where to get the ADR reporting forms [17]. This is not in correlation with findings from the current study where $68.18 \%$ of pharmacy staff knew where to get the ADR reporting forms. Studies elsewhere recorded generally poor knowledge in ADR reporting among healthcare professionals, contrary to what this current study found [19]. The high level of knowledge on ADR reporting from the present study might be due to the interventions that were instituted by the NAFDAC in 2015 to improve the ADR reporting in Katsina and Kano state, Nigeria. It could also be due to sensitization of health professionals during public health programs like the mass drug administration and the Seasonal Malaria Chemoprevention (SMC) which staff of the hospitals under study were part.

This study documented varied reasons for not reporting negative drug reactions. Relative to those that saw ADRs but did not report, the major reasons were the non-availability of the reporting forms and the not knowing the reporting procedure $(89.96 \%$ and $3.72 \%)$. Related outcomes were observed in other studies among pharmacists [20]. This calls for NAFDAC to ensure the provision of ADR forms to health facilities and the need to continuously orient health staff on ADR reporting.
The online reporting portal and the ADR forms were not accessible to almost 58\% and $89.96 \%$, respectively, of the respondents, and most of them were not trained or oriented on pharmacovigilance though most of them ever reported ADRs. The present study found similarities with a study in Uganda that found $56 \%$ of health professionals to have lacked training on ADR reporting [21]. Qassim also documented related findings among pharmacists [20]. These observations may be attributed to the fact that the ADR system is still developing, and the hospital has not assumed full responsibility for pharmacovigilance activities. It could also be due to inadequate policy direction or dissemination on making ADR reporting an integral part of the health system.

Respondents' perspective of how to improve ADR reporting was through training (100\%), patient education (98.4\%), ensuring the availability of ADR forms (97.9\%), and integrating ADR reporting into the monthly cases and deaths (CD1) reporting system (93.8\%). Patients that were aware and knew about the ADR reporting system reported the ADRs they experienced to a health professional [22].

\section{Limitations of the Study}

The study did not cover all health professionals due to financial and time constraints; hence sample was drawn from the target population for the study. There could be a recall and personal bias by respondents that could have an effect on the data and the outcome of this study.

Data provided about the number of ADR ever seen and reported could not be independently verified and authenticated. Findings from the study are limited to only the nineteen [19] Government hospitals in Katsina state, Nigeria, and should therefore be interpreted with the above limitations in mind. 


\section{Conclusion}

The Government hospitals in Katsina state, Nigeria, has a low ADR reporting rate. Medical Doctors and pharmacy staff reported more ADR cases than the nurses and midwives. Most health professionals that saw ADR in the past year reported it by completing the ADR reporting form. Knowledge of ADR reporting was generally high. The main systemic challenges with ADR reporting were the lack of access to ADR reporting form and an online portal on ADR reporting though it was one of the strategies to improve ADR reporting in Nigeria. Training and access to the ADR reporting tools are relevant to increasing the current ADR reporting rate of the Government hospitals in Katsina state, Nigeria.

\section{Recommendations}

1. All health professionals in close contact with the patient should be given access to the online reporting portal for ADR.

2. The NAFDAC should ensure regular training of all clinical cadres of health staff to

\section{References}

[1] Smith-Marsh, D. E. (2016), Adverse Drug Reactions (Adverse Drug Effects). Merck Sharp \& Dohme Corporation, 42(1), 12-16. Retrieved from http://www.msdmanuals.com/professional/clinicalpharmacology/adverse-drug-reactions/adverse-drugreactions.

[2] Nwokike, J., \& Eghan, K. (2010), Pharmacovigilance in Ghana: A Systems Analysis.

[3] Dodoo, A., \& Olsson, S. (2011), The world medicines situation 2011 pharmacovigilance and safety of medicines. WHO/EMP/MIE/2011.2.7.

[4] Oshikoya, K. A., Awobusuyi, J.O., (2009), Perceptions of doctors to adverse drug reaction reporting in a teaching hospital in Lagos, Nigeria. BMC Clin Pharmacol. 2009 Aug 11; 9:14. doi: 10.1186/1472-6904-9-14.

[5] Okezie, O.O., Fawole, O.I., (2008), Adverse drug reactions reporting by physicians in Ibadan, Nigeria. Pharmaco Epidemiol Drug Saf. 2008; 17: 517-522. improve the rate of ADR reporting in hospitals.

3. NAFDAC should consider linking the online reporting system to WhatsApp to facilitate reporting of ADR.

4. Hospital management should include ADR reporting in the appraisal of its staff to compile them look out for, and report ADRs.

5. Future research could be done to evaluate the whole pharmacovigilance system in the Katsina State focusing on the minimum requirement and what is currently practiced.

\section{Conflicts of Interest}

The authors declare that they have no conflicts of interest.

\section{Acknowledgements}

We wish to acknowledge Katsina State Ministry of Health, the Hospital Services Management Board, the 19 General Hospitals where the research was conducted, and the respondents.

[6] Ohaju-Obodo, J.O., Iribhogbe, O.I., (2010), Extent of pharmacovigilance among resident doctors in Edo and Lagos states of Nigeria. Pharmaco Epidemiol Drug Saf. 2010; 19: 191-195.

[7] Güner, M. D., (2017)' Incentives to Increase Pharmacovigilance Practices from an Educational and Ethical Point of View. Journal of Pharmacology \& Clinical Research, 3(5).

[8] Ezeuko, A.Y., Ebenebe, U.E., Nnebue, C.C., Ndu, O.O., (2015), Adverse Drug Reaction Reporting by Different Categories of Healthcare Workers in Nnewi, Nigeria: Awareness, Knowledge and Attitudes; BJMMR, 7(11): 932-941, 2015.

[9] World Health Organization. (2002), The Importance of Pharmacovigilance - Safety Monitoring of medicinal products. World Health Organization, $1-52$. https://doi.org/10.1002/0470853093. 
[10]Hazell, L., Shakir, S.A., (2006). Underreporting of adverse drug reactions: A systematic review. Drug Saf. 2006; 29:385-396.

[11] State News Letter (SNL) (2005), Addressing Maternal Mortality. Aminia 14: 5-13.

[12] Cochran, W.G., (1963), Sampling Techniques, Wiley, New York.

[13] Amedome, S.N., (2017), Pharmacovigilance Practices: Knowledge and Attitudes among the Healthcare Professionals at the Volta Regional Hospital of Ghana. https://doi.org/10.4172/23296887.1000229.

[14]Ekmekci, P. E., (2019), Healthcare professionals' pharmacovigilance knowledge and adverse drug reaction reporting behavior and factors determining the reporting rates. 8(1), 13-20. https://doi.org/10.1080/21556660.2019.1566137.

[15] Sabblah, G. T., Akweongo, P., Darko, D. M., Dodoo, A. N. O., \& Sulley, A. M. (2014), Adverse drug reaction reporting by doctors in a developing country: a case study from Ghana. Ghana Medical Journal, 48(4), 189-193. https://doi.org/10.4314/gmj.v48i4.4.

[16]Bahekar, S. E., \& Patil, S. M., (2018), Evaluation of knowledge, attitude, and practice of adverse drug reactions reporting among doctors and nursing staff of a rural tertiary care teaching hospital of

Maharashtra.

https://doi.org/10.4103/JMISR.JMISR.

[17] Kopciuch, D., Paczkowska, A., \& Ratajczak, P., (2019), Safety of medicines — Pharmacists' knowledge, practice, and attitudes toward pharmacovigilance and adverse drug reactions reporting process. (August 2018), 1-9. https://doi.org/10.1002/pds.4792.

[18]Bello, S., Tukur, U. M., (2011), Original Article Knowledge and attitudes of physicians relating to reporting of adverse drug reactions in Sokoto, northwestern Nigeria. https://doi.org/10.4103/15963519.76563 .

[19]Almandil, N.B, (2016), Healthcare professionals' awareness and knowledge of adverse drug reactions and pharmacovigilance. Saud Med J.;37(12):1359-64.

[20] Qassim, S., Metwaly, Z., Shamsain, M., and AlHariri, Y., (2014), Spontaneous Reporting of Adverse Drug Reactions in UAE: Obstacles and Motivation among Community Pharmacists. Qassim et al., 5(10), 4203-4208. https://doi.org/10.13040/IJPSR.09758232.5(10).4203-08.

[21] Katusiime, B., Semakula, D., \& Lubinga, S., (2015), Adverse drug reaction reporting among healthcare workers at Mulago National Referral and Teaching hospital in Uganda. Afri Health Sci., 15(4):1308-1317. [Online] Available at http://dx.doi.org/10.4314/ahs.v15i4.34.

[22] Jacobs, T. G., Hilda Ampadu, H., Hoekman, J., Dodoo, A. N. O., \& Mantel-Teeuwisse, A. K., (2018), The contribution of Ghanaian patients to the reporting of adverse drug reactions: A quantitative and qualitative study. BMC Public Health, 18(1), 111. https://doi.org/10.1186/s12889-018-6285-9. 